\title{
'CELESTINA' DE FERNANDO DE ROJAS: DOCUMENTO BIBLIOGRÁFICO (decimosexto suplemento)
}

\author{
Joseph T. Snow \\ Martín Reyes-Durán \\ Michigan State University
}

Siempre es grato agradecer el envío de materiales que entran en estos suplementos. Esta vez, gracias a P. Botta, J. L. Canet, lan MacPherson, y Celia Seniff. Este suplemento está dominado por los artículos en las actas del congreso de Purdue (1991), del cual una reseña aprecerá en el 17.2.

N.B. Utilizamos en este suplemento una abreviatura convencional ( $=$ Fifth Centenary) para señalar las entradas correspondientes a las actas del simposio internacional de 1991, celebrada en West Lafayette, Indiana, USA (ver CORFIS, abajo). [Ed.]

523. ARDEMAGNI, Enrica. "Celestina's Laboratory: A Translator's Dilemma," Fifth Centenary: 383-391.

Confronta el dilema que encara a los que pretenden traducir Celestina; dilema debido a las múltiples opciones de palabras y terminologías que se pueden usar, o debido a los contextos culturales e históricos diferentes que las traducciones de este texto de por sí encierran. Se hace mención a la traducción de James Mabbe hecha en 1631 al inglés, The Spanish Bawd, Represented in Celestina: or, the Tragicke-Comedy of Calisto and Melibea, y saca varios ejemplos de la traducción italiana de Ordóñez (1506). 
524. BEARDSLEY, Jr., Theodore S. "Kaspar von Barth's Neo-Latin Translation of Celestina (1624)," Fifth Centenary: 237-250.

Presenta un análisis parcial de la traducción al latín de Celestina, hecha por Kaspar von Barth (1624). Está obviamente escrita no por un latino-parlante sino más bien por un alemán. Sin embargo, las anotaciones de Barth al texto constituyen el primer intento académico de hacer una edición crítica (ejemplificado con varios modelos, entre ellos, el caso de 'huevos asados'). Ediciones también útiles para comprender su modus operandi son la de Gérard J. Brault, Célestine, A Critical Edition of the First French Translation (1527), y la de Kathleen V. Kish, An Edition of the First Italian Translation of the "Celestina".

525. BERNDT KELLEY, Erna. "Mute Commentaries on a Text: The Illustrations of the Comedia de Calisto y Melibea," Fifth Centenary: 193227.

Analiza clara y concisamente algunas de las ilustraciones que acompañan a la Celestina de ¿1499?. Señala que los tallados fueron incluidas para iluminar y reflejar fielmente las acciones descritas en el texto. Propone la idea que los artesanos contratados por Fadrique Alemán de Basilea, impresor de esta edición de Celestina, pudieron haber sido influenciados por otras ilustraciones que acompañan las obras de teatro de Johan Grüninger.

526. BOTTA, Patrizia, y Elisabetta VACCARO. "Un esemplare annotato della Celestina e la traduzione inglese di Mabbe." Cultura Neolatina 52 (1992): $353-419$.

Se trata de Biblioteca Nacional (Madrid) R/13.410, un ejemplar de la edición española plantiniana de 1599, profusamente anotado en inglés, en una mano que con casi toda seguridad es la de James Mabbe. Con una serie de agudas observaciones hechas por Botta, $y$ una serie de ejemplos presentados sistemáticamente por Vaccaro, ha sido posible reconstruir nuevas relaciones entre el manuscrito de Alnwick Castle (1598) y la traducción impresa en 1631 (ambas obras de Mabbe): ese manuscrito (desaparecido) habría contado con dos 'fuentes'-la traducción italiana de Hordognez (1506) y la ed. española plantiniana de 1595--y que, en su momento, modificado, produce el manuscrito extante (fechable ca. 1603-1611). Mabbe, al pensar su traducción de nuevo, tiene en mano la plantiniana de 1599 (el ejemplar encontrado ahora con sus anotaciones, o glosas, en inglés), y tiene su antiguo manuscrito (que nunca llegó a publicarse); utilizará ambos en producir una nueva traducción manuscrita hacia 
1629-1630, que es la que llega a imprimirse el año después. Un estudio de gran importancia.

527. BURKE, James F. "Law of the Father--Law of the Mother in Celestina," Fifth Centenary: 347-357.

La "ley del padre" es el orden simbólico basado en el lenguaje (y que ejerce autoridad moral). La "ley de la madre" es el imperio de la imaginación (en Rojas, el mundo de Celestina). En un estudio denso, B. quiere señalar como ninguna de las dos leyes puede sostener el mundo de manera completa, satisfactoria y la sensación de vacío que Pleberio desencadena en el último auto lo confirma.

528. CANET VALLES, José Luis. De la comedia humanística al teatro representable. Col.lecció Oberta, Serie Textos Teatrales Hispánicos del Siglo XVI, 2, Sevilla/Valencia: Univ. Nacional de Educación a Distancia [=UNED], 1993. Rústica, 398 pp.

Contiene una introducción (11-89, con una bibliografía muy al día) que ilumina el período en que la comedia humanística comienza a ceder ante los intentos de la representación. Edita, con notas explicativas, cinco obras de los años 1513-1521, que se conocen tradicionalmente como las primeras imitaciones celestinescas, y son: Egloga de la tragicomedia de Calisto y Melibea, Penitencia de amor (ambas de P. M. Ximénez de Urrea), Comedia Thebayda, Comedia Hipólita, y Comedia Serafina (todas oficialmente anónimas, aunque Canet sugiere posibles autores, pp. 68-78).

529. CARPENTER, Dwayne E. "The Sacred in the Profane: Jewish Scriptures and the First Comedy in Hebrew," Fifth Centenary: 229-236.

Comenta brevemente la vida de Joseph ben Samuel Tsarfati (también conocido como Giuseppe Gallo); gran médico papal y académico judío de comienzos del siglo XVI. El artículo propone que Tsarfati supuestamente fue el primero en traducir Celestina al hebreo. (texto hoy perdido), además de escribir un poema introductorio, todavía extante, a la obra teniendo como personajes principales a Melibea y Calisto (mencionando a los personajes en ese orden). Analiza la importancia de este poema, y sus referencias bíblicas, litúrgicas, y talmúdicas, para las investigaciones actuales de Celestina con enfoque didáctico y religioso. 
530. CASTELLS, Ricardo. "El mal de amores de Calisto y el diagnóstico de Eras y Crato, médicos." Hispania 76 (1993): 55-60.

El autor prefiere la lectura de la CCM ("Eras y Crato") a la de la TCM (primero, "Crato y Galieno," y luego "Erasístrato"), siendo que estos dos médicos de la vista y del oído son los que hubieran entendido el mal de amores de Calisto (enfermedad que se producía a través de los ojos y de los oídos del galán). Hay referencias a tratados de amor y a episodios paralelos aparecidos en Tirant lo Blanc y en La vita nuova de Dante.

531. CORFIS, Ivy A., y J. T. SNOW, eds. Fernando de Rojas and "Celestina": Approaching the Fifth Centenary. Proceedings of an International Conference in Commemoration of the 450 Anniversary of the Death of Fernando de Rojas, Purdue University, 21-24 November 1991. Madison, Wisconsin: Hispanic Seminary of Medieval Studies, 1993. xx +439 pp.

Actas de un simposio: los estudios están anotados en este mismo suplemento.

532. (see SNOW, abajo, núm. 560).

533. DAVIES, G. A. "Destellos de un sub-texto literario. La rememoración del pasado en La Celestina." Leeds Papers on Hispanic Drama, ed. Margaret A. Rees (Leeds: Univ. of Leeds, Trinity and All Saint's College, 1991): 9-41. $\left({ }^{*}\right)$

534. DEBAX, Michelle. "El yo problemático en la Celestina." Compás de Letras 1 (1992): 64-74.

Hay un 'yo' aparente (el del paratexto, o sea, de los preliminares, posliminares, etc.) y un 'yo' oculto (el del texto Comedia / Tragicomedia) en Celestina. El acercamiento lingüístico al "hacer textual" podría servir para localizar la presencia del 'yo' oculto: por ejemplo, en considerar algunas de las expansiones o interpolaciones (Tragicomedia) en función de un 'yo' que así implica indirectamente el entendimiento del 'tú'-receptor, o tratar el doble nivel de los textos citados (autores clásicos, refranes en sus varios contextos) como otra manera que tiene el 'yo' de enganchar al 'tú', de llamarle la atención a la necesidad de sopesar siempre dos versiones de todo, proceso éste que se podría equiparar con el tema de 'contienda' que inicia el 'yo' aparente de los materiales preliminares. 
535. DEYERMOND, Alan. "Female Societies in Celestina," Fifth Centenary: 1-31.

Presenta cuatro tipos de micro-sociedades femeninas latentes en la Edad Media; 1 ) la corte u hogar: gobernado por la mujer cuyo marido se encuentra ausente; 2) el convento: donde las monjas conviven, aunque la vocación radique en la esperanza de encontrar una vida mejor fuera de sus hogares; 3 ) la hacienda de una viuda; $y$ 4) el burdel, micro-sociedad femenina que se ejemplifica plenamente en Celestina y cuyas implicaciones son ampliamente expuestas en este estudio. En la micro-sociedad de Celestina, es ella que rige y son los hombres los marginados: es interesante notar que esta microsociedad es la única proveniente del proletariado y también la única que, a últimas instancias, es destruida por la violencia de los hombres. Explica como las relaciones hombre-mujer (Calisto-Melibea, Pármeno-Areúsa) sirven para definir el cosmos de esta sociedad femenina, ya sea por motivaciones de comercio, de amor, o de lujuria.

536. FOTHERGILL-PAYNE, Louise. "'Conséjate con Séneca': Auctoritas in Celestina and Celestina comentada," Fifth Centenary: 113-128.

Esta Celestina Comentada, obra de un autor anónimo, escrita a mediados del siglo XVI, pone anotaciones a las palabras de los interlocutores de Rojas, con la ayuda de auctoritates. El artículo comenta el pasaje de Sempronio sobre los vicios de las mujeres (Aucto I), elucidando los procedimientos del comentarista al señalar una jerarquía de fuentes que comienza con André Tiraqueau y su De legibus connubialibus (1513) y llegan a Séneca, Ovidio, Juvenal, Petrarca, y otros. El cotejo de Rojas y su comentarista revela que el humor del autor fue recibido a veces con demasiado literalismo y seriedad.

537. FRAKER, Charles F. "The Four Humors in Celestina," Fifth Centenary: 129 154.

Cita estudios de J. W. Draper sobre los cuatro humores (sangre, flema, melancolía, cólera) en las tragedias de Shakespeare, y se pregunta si tal estudio ha de ser realizado con respecto a Celestina, adicionando los trabajos por F. de Armas y P. Cátedra. Hay dos dificultades a confrontarse: 1) la perspectiva bradeliana que obliga al lector a tratar a los personajes ficcionales como si fueran reales, 0 como si fueran concebidos de la misma manera que los personajes de la ficción clásica, 2) el hecho de que los personajes celestinescos son más difíciles de analizar en sus humores que los de Shakespeare. $\mathrm{Da}$ un buen resumen/definición de los cuatro humores (utilizando el Regimen sanitatis salernitanum), antes de adentrarse en el texto 
celestinesco. ¿Tenían Rojas y el presunto primer autor conocimientos de la teoría de los humores? ¿Está implícita o explícitamente presente en la obra? Sugiere los humores de unos personajes celestinescos (Pármeno y Sempronio-flemáticos; Celestina--melancólica y colérica; Elicia y Areúsa--coléricas, etc.).

538. FRIEDMAN, Edward H. "Rhetoric at Work: Celestina, Melibea, and the Persuasive Arts," Fifth Centenary: 359-370.

Al interesarse por el lenguaje retórico en Celestina, explica la dicotomía retórica/gramática: la primera es libre, sin reglas, mientras la otra es rígida y normativa. Por medio del modelo deconstructivo, muestra como la retórica y los códigos lingüísticos modifican y crean los papeles de cada personaje; y también como cada personaje se vale de las mismas técnicas lingüísticas para comunicar sólo a medias sus intenciones reales, a la vez que dejan entrever su realidad escondida. La destrucción de Melibea es una prueba de "como el poder del lenguaje puede dominar, excluir, mantener prioridades, y distanciar al hablante."

539. GARCI-GOMEZ, Miguel. "El cabello de Melibea (Medusa): Entre la petrificación y el emborricamiento," en Estudios en homenaje a Enrique Ruiz-Fornells, ed. J. Fernández-Jiménez et al (Erie, Pennsylvania: ALDEEU, 1990), pp. 233-239.

Los cabellos como fetiche sexual, como potencias para congelarle al hombre que los trasmuta por los pelos escondidos de la mujer en sus fantasías. La referencia es del auto $\mathrm{I}^{\circ}$, el diálogo entre Calisto y Sempronio. La exploración del símbolo del cabello--y del "emborricamiento" del hombre ante él--pasa por la sicología moderna, la mitología, la Biblia, y el Poema de Mio Cid.

540. GASCON VERA, Elena. "Visión y razón: elementos trágicos en La Celestina," en Estudios .. Ruiz-Fornells (Erie, PA: ALDEEU, 1990), pp. 246-254.

Explora el conflicto "luz/razón" en las imágenes y situaciones del texto para iluminar mejor su papel en las eventuales tragedias ocurridas a Calisto y Melibea por Sempronio (los jóvenes), y Celestina, Pleberio y Alisa (los mayores). Expone sistemáticamente los instantes de Celestina donde, ya sea por destino humano, codicia servil, o ya sea por las intervenciones de la vieja alcahueta, se vislumbran estos elementos trágicos entremezclados en la trama de la obra. Sostiene que la contienda o batalla en la que están configurados los personajes principales de la obra (contienda que será la causa de su destrucción moral y de su muerte) está ya 
determinada por el uso que hacen de sus facultades de la vista y de la razón: tal proceso de la destrucción moral es un eje organizador de la obra.

541. GIMENO CASALDUERO, Joaquín. "El mundo de La Celestina." Nueva Revista de Filología Hispánica 40 (1992): 99-116.

Llama la atención a la influencia que tuvo en Rojas las Coplas de Jorge Manrique; el cual a su vez ya había sido influenciado por las homilías de San Gregorio dedicadas al Evangelio. Se trata del ajuste--o transformación--que Rojas consigue, con respecto a las Coplas, del tono moralizador, asignando las diferencias a los dos mundos presentados: el del pecado y el de la gracia. Expone plenamente la relación opuesta que existe entre los escritos gregorianos y las adaptaciones manriqueñas de la trascendencia de la muerte--que moralizan dentro de este mundo de la gracia--con el mundo del pecado que expone Rojas; ya que aunque ambos mundos reflejan el dolor y la angustia relacionadas con la muerte, en uno existe la esperanza de la eternidad mientras que en el otro reluce la idea de la temporalidad.

542. KISH, Kathleen V. "Eighteenth Century Celestina Reincarnations," Fifth Centenary: 251-265.

Comenta el resurgimiento de Celestina después de la censura, a través del desarrollo de adaptaciones celestinescas en Inglaterra durante el siglo XVIII (y después), destacando las adaptaciones de John Savage ("Tragicomedia...adaptada al escenario Inglés"), del Capitán John Stevens (Celestina, the Bawd of Madrid), y de Ashley Dukes (Five Plays of Other Times). La traducción de Celestina por James Mabbe influye en algunas de estas adaptaciones. En las bellas artes, se destacan las pinturas de Goya: La madre Celestina, Maja and Celestina on a Balcony.

543. LACARRA, María Eugenia. "La evolución de la prostitución en la Castilla del siglo XV y la mancebía en Salamanca en tiempos de Fernando de Rojas," Fifth Centenary: 33-78.

Detalla la trayectoria histórica de las prostitutas en la Edad Media española, expone la definición de tales de acuerdo al Fuero /uzzo, junto con sus respectivas penalidades. Describe niveles de alcahuetería de acuerdo al Fuero Real y las Partidas; esta categorización alfonsi es esencial para la comprensión de la caracterización de la alcahueta de Rojas. Describe también el establecimiento de las mancebías y su trascendencia e influencia en la creación de leyes restrictivas durante estos siglos. Aclara, con 
ejemplos de Celestina, el paralelo de la prostitución y alcahueteria ficcionales con la realidad histórica de la época.

544. McGRADY, Donald, y Suzanne Freeman, eds. Lope de Vega, La bella malmaridada. Charlottesville, Virginia: Biblioteca Siglo de Oro, Num. 6, 1986.

En la introducción y las notas llaman la atención a la influencia de Rojas y Celestina en esta obra de Lope.

545. MACPHERSON, Ian. "Celestina labrandera." Revista de literatura medieval 4 (Madrid: Gredos, 1992): 177-186.

Expone un interesante recuento de las acciones ocurridas en el Aucto IV de Celestina; en el cual la vieja alcahueta hace su primera entrada en la casa de Melibea con el pretexto de vender un hilado (oficio de labrandera o costurera). Plantea interesantes preguntas acerca de las actitudes y acciones que presentan algunos de los personajes en este fatídico Aucto IV (entre otras preguntas; ¿por qué deja Alisa entrar a Celestina después de reconocerla? y ¿por qué deja a su hija sola con ella más adelante en la escena?) Comenta como Rojas posiblemente utilizó la escena diabólica con Celestina en el Aucto III para justificar la partida inverosímil de Alisa. Sin embargo, a través del uso de la ironía verbal y dramática, Rojas también hace una retrato caricaturesco y cruel de la burguesía al presentar a Alisa como una mujer tonta, ciega, irreflexiva, antipática y muy crédula.

546. MALKIEL, Yakov. "Analysis of Early Critical Reactions to María Rosa Lida de Malkiel's La originalidad artística de 'La Celestina'," Fifth Centenary: 79-92.

El libro de 1962 hizo época, eso sí. Aquí, casi 30 años después, se intenta matizar las más de 70 reacciones al libro (mayormente reseñas) que reconocieron anticipadamente los que serian sus valores permanentes.

547. MIGUEL MARTINEZ, Emilio de. "Celestina, teatro," Fifth Centenary: 321345.

La esencia dramática y teatral de Celestina se propone en este estudio desde una docena de perspectivas (teóricas, prácticas), y con una energía poco usual hasta la fecha. Quienes abogan por una naturaleza novelística para Celestina tendrán que confrontar los argumentos aqui ofrecidos, y en su conjunto. 
548. MUÑOZ, Raul. "La función temática de los objetos inanimados en La Celestina," en Estudios ... Ruiz-Fornells (Erie, PA: ALDEEU, 1990), pp. 432-437.

Señala que en Celestina se encuentra un gran número de objetos inanimados (huerto, torre, escaleras, ventanas, calles, puertas, paredes, murallas ) que adquieren gran importancia como elementos indispensables a la estructura irónica de la obra. Pretende enfocar la atención a estos objetos más como barreras simbólicas al amor sensual y a la engañosa naturaleza humana que meros elementos decorativos del espacio físico.

549. PEREZ PRIEGO, Miguel Angel. "Celestina en escena: el personaje de la vieja alcahueta y hechicera en el teatro renacentista," Fifth Centenary: 295-319.

Sigue las huellas del personaje celestinesco en estas obras del siglo XVI: la Egloga de Plácida y Vitoriano (h. 1513), la Egloga II de Ximénez de Urrea (h. 1516), la Comedia Tidea (pre-1550), el Auto de Clarindo (h. 1535), la Comedia Pródiga (pre-1554), la Farsa de la hechicera (pre-1547), y la Farsa de la Esposa de los Cantares (h. 1560)). Con muchas citas textuales.

550. RANK, Jerry R. "'O cruel juez, y que mal pago me has dado ...: Or Calisto's Urban Network," Fifth Centenary: 155-164.

Fernando de Rojas provee a sus personajes con un pasado, para que de esta manera entendamos sus acciones dentro del marco celestinesco y las circunstancias sociales que los rodean. Como ejemplo, nos da Calisto como un aristócrata urbano, y nos deja entrever ciertos lazos íntimos--si no corruptos-entre el cruel juez del auto XIV y la familia de Calisto. Celestina puede servir para entender cómo era la sociedad urbana del siglo XV (una mezcla de prostitutas, alcahuetas, corrupción, contrabando y soborno).

551. RICAPITO, Joseph V. "People, Characters, and Roles: A View of Characterization in Celestina," Fifth Centenary: 181-191.

Utiliza los trabajos de Lida de Malkiel y Gilman para repasar los estrechos vínculos que unen los personajes celestinescos y los modelos de la comedia humanística. Da amplios ejemplos de como el diálogo y las acciones se convierten en elementos fundamentales para la creación de nuevas dimensiones en la caracterización de ellos, a quienes clasifica en tres categorías; 1 ) los convencionales (Calisto, Sempronio y Elicia), 2) los que se alejan un poco de las tipologias 
convencionales (Pármeno y Areúsa), y 3) los que se alejan más de las tipologias (Melibea y Pleberio). Celestina es categoría aparte.

552. RODRIGO, Antonina. Margarita Xirgu y su teatro. Barcelona: Planeta, 1974.

En las páginas 276 y 297-300 se encuentran interesantes detalles sobre la representación de Celestina que hizo la Xirgu en Montevideo (1949) y Buenos Aires (1956). Foto entre 304-305.

553. ROUND, Nicholas G. "Celestina, Aucto I: A Platonic Echo and Its Resonances," Fifth Centenary: 93-112.

Depende del lector y la lectura que se haga de un texto el observar trazas de influencias de otros autores u otros textos. Múltiples relecturas y el estado anímico del momento pueden resultar en conclusiones diversas. De su propia lectura de Celestina, Round identifica en el auto $1^{\circ}$ unas instancias donde se encuentran ecos de Platón. Estos sirven para descartar a Mena y a Cota como posible Antiguo Auctor, aunque si recalca el hecho de que tal autor debía ser de una generación anterior a la de Rojas. A su vez propone a Fernando de Roa profesor de Rojas en Salamanca) como candidato.

554. SABAT DE RIVERS,Georgina. "Los problemas de La segunda Celestina." Nueva revista de filologia hispánica 40 (1992): 493-512.

Después de todo lo escrito sobre la autoría/no autoría de Sor Juana Inés de la Cruz de un tercer auto de la comedia comenzada en España por Salazar y Torres en 1575 (comedia también acabada por Vera Tassis), titulada "La Segunda Celestina" (Vera Tassis: "El encanto es la hermosura"), Sabat de Rivers repasa minuciosamente los argumentos y la evidencia y, sin poder resolver la cuestión, sí demuestra que no se puede eliminar a Sor Juana como candidata, como algunos han pretendido hacer.

555. SALVADOR MIGUEL, Nicasio. "'De una ave llamada rocho': para la historia literaria del ruj," Fifth Centenary: 393-411.

Esta referencia a una ave fantástica aparece en el prólogo a la Tragicomedia, y en este artículo, se estudia la etimología de la palabra y su historia durante y después de la Edad Media. 
556. SCHIZZANO MANDEL, Adrienne. "Celestina's Seductive Power in France: An Operatic Debut," Fifth Centenary: 283-293.

Historia y significado de la obra operática de Maurice $\mathrm{O}^{\prime} \mathrm{Hana}$ que tuvo su estreno en París en 1988. Describe, escena por escena, el progreso de la acción (y la música), con un sentido crítico y comparativo (con la obra de Rojas).

557. SENIFF, Dennis P. Antologia de la literatura hispánica medieval. Biblioteca Románica Hispánica VI. Antología Hispánica, 38, Madrid: Gredos, 1992.

En esta novísima antología, los excerptos de Celestina (llamada 'novela dialogada'; propone a Cota como probable colaborador de Rojas) están en las páginas 621-45. Da una idea de la obra, sobre todo del primer auto. Hay un ensayo bibliográfico en 62 y una lista de estudios $y$ otros comentarios en 114-117.

558. SEVERIN, Dorothy S. "Celestina as a Comic Figure," Fifth Centenary: 165179.

Con citas generosas de los actos en que aparece Celestina, nos hace sentir como varias escenas--unas de humor ligero, otras con más sátira--son (o podrán ser) recibidas por los oyentes de la Tragicomedia. Tanto depende, con todo--la autora señala--en el arte de la intérprete en el papel de Celestina.

559. SNOW, Joseph Thomas. "Five Centuries of Celestina Readings: An Overview and an Example From the Nineteenth Century," Fifth Centenary: 267-281.

La idea es que las obras celestinescas pueden estudiarse para sacar de ellas diversas fuentes de inspiración particulares encontradas por estos lectores/autores en la obra de Rojas, y asi ir comprendiendo mejor las verdaderas ( $y$ a veces sorprendentes) dimensiones de ella. Aquí el ejemplo comentado es S. Estébanez Calderón, su artículo costumbrista, "La Celestina" (hacia 1843).

560. (con Ivy A. Corfis). "Celestina and Celestinas: Nearing the Fifth Centenary," Fifth Centenary: xi-xx.

Intenta dar una visión panorámica de la prole de Celestina después de publicada la inmensamente popular Tragicomedia. Sólo tiene como finalidad realzar la extraordinaria riqueza creadora que la obra original ha estimulado a lo largo de casi cinco siglos. 
561. STAMM, James R. "Reading and Listening in Celestina," Fifth Centenary: 371-381.

Define dos significados del verbo leer presentes en la Comedia; (1) leer la obra para sí mismo y, (2) leer la obra para un público. Señala como Alonso de Proaza (corrector de la obra) promueve la segunda opción, mientras la lectura silenciosa es lo que se sospecha para Rojas. Aduce ejemplos para demostrar como el texto mismo se inclina por la adquisición de sabiduría en una forma oral (Pármeno), mientras que en otras instancias se adquiere por medio de la palabra escrita (Melibea). Pero de los dos, el habla se representa con más frecuencia (refranes, anécdotas, proverbios etc.). De los siete personajes principales, Celestina, Pármeno y Areúsa utilizan el habla; Calisto, Melibea y Pleberio utilizan la lectura, mientras que Sempronio utiliza ambos.

562. VILANOVA, Antonio, ed. Francisco Delicado. La lozana andaluza. Barcelona: Selecciones Bibliófilas, 1952.

Esta edición contiene un prólogo (XI-LX) que tiene una breve presentación de la vida de Francisco Delicado, y de la importancia histórica y lingüística de La Loçana andaluza. La obra en sí incluye la primera proyección de la novela celestinesca española por el suelo italiano, además de señalar el inicio de la picaresca dentro del mundo rufianesco de la prostitución romana. La obra presenta la vida de una nueva Celestina cordobesa entre las meretrices romanas y las cortesanas españolas en Italia. Facsímil de la portada de la primera edición de Loçana en la página iv.

563. WHITBOURNE, Christine. Knaves and Swindlers: Essays on the Picaresque Novel in Europe. London/New York/Toronto: Oxford UP, 1974.

En el primer ensayo, "Moral Ambiguity in the Spanish Picaresque Tradition," se arguye la importancia de Celestina en el trayecto de la ficción picaresca, tanto en el caso de ciertos personajes como en su estilo y retórica (ver, especialmente, las pp. 4-7 y 14) 